\title{
O PSICOTERAPEUTA E A ESCOLHA DO MATERIAL NO PROCESSO DE LUDODIAGNÓSTICO
}

\author{
Adriana Trapiá \\ Psicóloga. Faculdades Metropolitanas Unidas - FMU. \\ Caroline Tagliapietra \\ Psicóloga. Faculdades Metropolitanas Unidas - FMU. \\ Eric Usui \\ Psicólogo. Faculdades Metropolitanas Unidas - FMU. \\ Maitê Hammoud \\ Psicóloga. Faculdades Metropolitanas Unidas - FMU. \\ Tamyris Lino Coelho \\ Psicóloga. Faculdades Metropolitanas Unidas - FMU.
}

\begin{abstract}
Resumo
O presente artigo apresenta um estudo bibliográfico acerca dos aspectos a serem observados na escolha do brinquedo e do brincar no processo de ludodiagnóstico. Para tanto, utilizou-se, principalmente, contribuições teóricas psicanalíticas de A. Freud, M. Klein e D. W. Winnicott. Discutiu-se o papel do psicoterapeuta, o setting terapêutico e o significado do brinquedo e do brincar. Concluiu-se que o psicoterapeuta possui papel fundamental na escolha do material e do ambiente no processo de ludodiagnóstico. E que uma atitude adequada, do profissional, considera as variáveis do ambiente, adapta os brinquedos e a brincadeira à capacidade cognitiva da criança, e, simultaneamente, respeita o processo de maturação e permite a livre expressão.
\end{abstract}

Palavras-chave: brincadeiras e brinquedos; diagnóstico; psicanálise.

\section{PSYCHOTHERAPIST AND THE CHOICE OF STUFF IN THE PROCESS OF LUDODIANOSTIC}

\begin{abstract}
The article presents a bibliographic study about the aspects to be observed in the choice of the toy and the act of play in the ludodiagnostic process, for that, it was used mainly, theorical contributions of A. Freud, M. Klein and D. W. Winnicott. It was discussed the role of the psychotherapist, the therapeutic setting, and the meaning of the toy and playing it. That shows that the psychotherapist have an fundamental role in the choice of the material and the ambience in the ludodiagnostic process and it's an right attitude of the professional if he considers the variables of the ambience, adapts the toys and the play into the cognitive capacity of the children and simultaneously respects the process of maturation and allows the free expression.
\end{abstract}

Keywords: plays and toys; diagnostic; psychoanalysis. 


\title{
EL PSICOTERAPEUTA Y EL SELECCIÓN DEL MATERIAL EN PROCESO LUDODIAGNÓSTICO
}

\begin{abstract}
Resumen
Este artículo presenta un estudio bibliográfico sobre el aspectos que deben ser observados en la elección del juguete y del jugar en el proceso de ludodiagnóstico, por lo tanto, se utiliza principalmente aportaciones teóricas psicoanalíticas de A. Freud, M. Klein y D. W. Winnicott. Se discutió el papel del psicoterapeuta, el setting psicoterapéutico y el significado del juguete y del jugar. Se concluyó que el psicoterapeuta tiene papel importante en la elección del material y del medio ambiente en el proceso de ludodiagnóstico. También se observó que una actitud adecuada, profesional, considera que las variables del entorno, el ajuste de los juguetes y diversión a la capacidad cognitiva del niño, al mismo tiempo respeta el proceso de maduración y permite la libertad de expresión.
\end{abstract}

Palabras claves: juguetes y diversión; diagnóstico; psicoanálisis.

\section{INTRODUÇÃO}

As avaliações psicológicas dos sintomas envolvem um processo que pode ter um ou vários objetivos. Cabe ao profissional de Psicologia a escolha de quais instrumentos utilizará na investigação. A primeira etapa para o início do ludodiagnóstico denomina-se processo de investigação. O processo engloba a coleta de informações sobre a história pessoal ou familiar do sujeito, associadas à pesquisa do ambiente atual e entrevista com os pais, possibilitando a investigação dos sintomas na estrutura familiar e levantamento de hipóteses diagnósticas. Somente a partir de tais hipóteses, é que o psicólogo poderá elaborar estratégias de investigação para dar entendimento ou solução para o problema/sintoma que motivou a procura pelo profissional (Affonso, 2012).

Mas o que observar na escolha do material utilizado no ludodiagnóstico?

Crianças e adolescentes que não dispõem de recursos para externalizar seus conteúdos latentes num processo de psicodiagnóstico, podem acessar e nos mostrar este material de forma lúdica. Foi pensando nisso que Klein (citada por Affonso, 2012) fundamentou sua teoria de ludoterapia. Por meio da utilização de simbolismos, crianças e adolescentes poderão expressar conteúdos inconscientes, possibilitando que o psicoterapeuta identifique angústias e limitações que serão de suma importância serem trabalhadas para o desenvolvimento destes e para que seja possível a orientação de seus familiares a fim de facilitar o processo para ambos.

A ampliação dos conhecimentos teóricos, a prática profissional e o desenvolvimento das capacidades dos psicólogos podem propiciar uma escolha mais adequada do material de trabalho, de forma a determinar um diagnóstico 
assertivo que possibilitará uma visão totalizadora do indivíduo, abrangendo suas dinâmicas intrapsíquicas, intrafamiliares e socioculturais, como forças e conjunto de forças em interação, que resultam em desajustamentos individuais, tendo presente os dinamismos do desenvolvimento e maturação do indivíduo (Trinca et al, 1984). Cabe ao profissional o uso de sua percepção aguçada para escolha correta do material, que, possivelmente, facilitará a comunicação simbólica com a criança, mobilizando conteúdos específicos que sejam relevantes a serem investigados.

Atualmente existem diversos recursos que possibilitam o trabalho no ludodiagnóstico, dentre eles estão: a observação e a entrevista psicológica - que podem ser realizadas com a criança, com os pais, ou com aqueles que 0 profissional julgar necessário; os testes psicológicos - capazes de avaliar não só a capacidade intelectual e seu desenvolvimento como também possíveis comprometimentos neurológicos e limitações do indivíduo e a caixa lúdica material tradicionalmente utilizado nos processos de ludodiagnóstico - que implica ao profissional o manejo da escolha dos brinquedos como facilitador para o processo.

O significado do brinquedo pode ser um tema polêmico, na medida em que os psicoterapeutas ou profissionais da saúde não consideram os significados dos brinquedos como algo estático e imutável. Além disso, o estudo do significado do brinquedo envolve necessariamente estudar a sua evolução no contexto de diversas culturas. Podemos contar com contribuições de alguns autores no desenvolvimento deste trabalho para escolha e significação de brinquedos e jogos tais como: A. Freud, M. Klein e D. W. Winnicott.

O jogo é fundamental no psicodiagnóstico compreensivo e interventivo e no tratamento psicoterápico de crianças. Sua relevância e abrangência ultrapassam os limites da clínica com as crianças (Affonso, 2012).

Winnicott (1975), a partir dos seus estudos na clínica infantil, defende a tese de que é necessário estudar o brincar como um fenômeno de formas diferenciadas, onde a brincadeira facilita o crescimento, desenvolvendo o potencial criativo e conduz para relacionamentos grupais. Nesse sentido, o autor entende que o brincar é uma terapia com possibilidade auto curativa, único veículo possível de expressão para as crianças, como meio privilegiado de expressão e de apreensão da realidade, onde o brincar permite o acesso ao simbólico e aos processos complexos da vida. 
O objetivo deste estudo é analisar os aspectos a serem observados pelo psicoterapeuta durante a escolha do material utilizado no ludodiagnóstico, tendo como base o referencial teórico psicanalítico

\section{MÉTODO}

A metodologia utilizada foi de estudo bibliográfico de autores com embasamento teórico psicanalítico acerca dos aspectos a serem observados pelo psicoterapeuta na escolha do material utilizado no processo de ludodiagnóstico. Para isso foram analisados livros e artigos científicos consultados nas bases de dados eletrônicas Scielo e Lilacs, tendo como descritores: Brincadeiras e brinquedos; diagnóstico; psicanálise.

\section{RESULTADOS E DISCUSSÃo}

Para iniciar as reflexões acerca do papel do psicoterapeuta e dos aspectos a serem observados na escolha do brinquedo e do brincar no processo de ludodiagnóstico, os autores estudados mostram se basear em teorias por vezes distintas a respeito do tema, apresentando contribuições a partir do seu exercício clínico e embasamento teórico. Os principais autores citados para o embasamento deste artigo foram Klein, Anna Freud e Winnicott. Klein (citada por Lebovici \& Diatkine, 1998) utiliza-se da teoria do splintting, Winnicott (1975) cria a teoria da brincadeira e Anna Freud (citada por Ferro, 1995) desconsidera a transferência em crianças.

Klein (citada por Lebovici \& Diatkine, 1998) tinha o jogo como método essencial para tratamento psicanalítico de crianças, considerando que o brinquedo era uma expressão direta de suas fantasias masturbatórias. Neste aspecto, o sonho tem a mesma função de satisfazer os desejos infantis, ou seja, a personificação do brinquedo é uma amostra da não inibição das fantasias. As figuras que aparecem no brinquedo são intermediárias entre os aspectos ferozes do superego e as identificações próximas da realidade, entre as imagens prégenitais e as imagens edípicas. A partir disso, Klein, se utiliza da teoria de splitting colocando o mundo dos objetos parciais internalizados em contraposição ao dos objetos do brinquedo personificado que se tornam um suporte projetivo, havendo assim uma projeção lúdica que possibilita a diminuição de conflitos internos. 
Entendemos que a criança por meio do brinquedo tem a possibilidade de projetar o bom e o mal, podendo vivenciar novas experiências para a resolução dos seus conflitos internos.

Anna Freud (citada por Ferro, 1995) afirmava que as crianças não têm capacidade de transferência por não terem ainda desatado as suas ligações externas originais. Esta autora valoriza o sonho, as fantasias diurnas e os desenhos e limita a utilização de jogos.

Winnicott (1975) cria a teoria da brincadeira, onde descreve um processo pelo qual o bebê se relaciona com as figuras parentais e com as outras pessoas durante o seu desenvolvimento, e tenta vincular o brincar com cada momento. A sequência tem quatro momentos, sendo o primeiro quando o bebê e a figura materna estão fundidos, onde o bebê tem uma visão subjetiva do objeto e a mãe tenta tornar concreto aquilo que o bebê está pronto a encontrar. No segundo momento o bebê repudia a mãe, aceita de novo e a percebe objetivamente. A forma como a mãe participa deste movimento do bebê e devolve o que é abandonado viabiliza que ele vivencie a experiência de controle mágico ou a onipotência. A confiança na mãe cria um playground intermediário onde a ideia de magia se origina. No estágio seguinte a lembrança da pessoa que lhe dá segurança é suficiente para que a criança fique sozinha na presença de um terceiro. No quarto e último estágio a criança permite uma superposição das brincadeiras, a mãe brincar com o bebê e mais tarde o bebê brincar sozinho, aceitando ou não ideias que não são próprias e por último o brincar em conjunto num relacionamento. Para Winnicott é somente no brincar que a pessoa, criança ou adulto, pode através da criatividade utilizar a sua personalidade integral, indo ao encontro do descobrimento do seu self.

Winnicott (1975) postula que as relações que acontecem no brincar, que se iniciam nos primeiros contatos do bebê com a figura materna, fazem parte do processo evolutivo e perduram até o fim da vida.

Froebel (citado por Pickard,1975 \& Affonso, 2012) destaca a importância da observação da fase de desenvolvimento cognitivo da criança para a realização do processo de ludodiagnóstico e de psicoterapia. Afirma que é importante considerar a individualização por existir uma mudança radical de uma fase para outra. Affonso (2012) considera que a brincadeira simbólica faz parte das etapas do processo de socialização da criança, por isso a escolha de determinado brinquedo ou brincadeira pela criança será analisada sob o enfoque evolutivo. 
É importante que a escolha do brinquedo feita pelo psicoterapeuta seja coerente com a idade da criança, para evitar a mobilização de angústia perante a sua apresentação, pois poderá mobilizar frustrações pela falta de capacidade cognitiva da criança em utilizar aquele brinquedo. Por exemplo, apresentar o jogo banco imobiliário para uma criança de seis anos poderá causar um estranhamento e sentimentos negativos, porém deve-se permitir que a criança utilize os brinquedos com liberdade, respeitando a sua necessidade de regredir ou avançar, podendo colocar a sua criatividade em prática.

O lúdico no processo de psicodiagnóstico permite ao psicoterapeuta compreender a natureza do pensamento infantil, onde há fornecimento de informações significativas que possibilitam a formulação de conclusões diagnósticas e intervenções terapêuticas. Para isso, a a postura do psicoterapeuta na escolha do material é fundamental, pois este deve viabilizar que a criança se expresse de maneira a não se sentir ameaçada frente à experiência, criando boas condições para que a mesma possa brincar com a maior espontaneidade. Ocampo (1999) postula que cooperar com a criança é função específica do psicólogo, assim como observá-la e compreendê-la.

Winnicott (1975) e Klein (citada por Lebovici \& Diatkine, 1998) convergem que o psicoterapeuta deve permitir a manifestação da capacidade que o paciente tem de brincar e de ser criativo no processo, abrindo espaço para que ele haja livremente. Winnicott tem como premissa que o paciente e psicoterapeuta precisam conseguir brincar, caso um destes não consiga, o psicoterapeuta deve, primeiramente, trabalhar para o desenvolvimento desta capacidade. Segundo Ferro (1995), ao utilizar jogos, o psicoterapeuta deve considerar a necessidade de participar da brincadeira por ser de fundamental importância a presença do outro, ou seja, que haja alguém com quem brincar.

O brinquedo por si só pode ajudar a criança a representar e tentar encontrar soluções para os próprios conflitos, mas somente a presença mental de alguém mais que brinque com ela é o que permite que o jogo seja plenamente transformador de angústias. É a acolhida dos estados mentais e emocionais presentes durante o jogo que consente as transformações mais profundas.

Affonso (2012) complementa que é necessário evitar restrições na maneira do brincar, preparando devidamente o local que será utilizado pela criança. 0 local deve permitir que a criança movimente-se, pinte a mesa ou a parede, jogue 
bola, molhe com água, etc. de forma a permitir eventualidades, descontroles lúdicos e a reparação diante do descontrole.

Outro aspecto que o psicoterapeuta deve observar na escolha do brinquedo é o seu tamanho - Klein (citada por Affonso, 2012) sugere que os materiais sejam pequenos, permitindo que a criança os manipule, ou seja, tenha controle sobre os mesmos, mas não tão pequenos que possam colocar sua vida em risco. É importante que os materiais estruturados sejam uma miniatura da realidade, para que a criança possa encontrá-los e reconhecê-los como representantes da sua realidade.

Analisar a forma atual do ludodiagnóstico nos levou a questionar, assim como Affonso (2012), a apresentação da caixa lúdica neste processo, refletindo sobre o quanto manter uma caixa lúdica coletiva interfere no sigilo, no vínculo e no processo de avaliação da criança, considerando a preservação da sua individualidade, pois a caixa lúdica representa o mundo interno da criança.

É importante que a escolha dos materiais e do ambiente pelo psicoterapeuta seja cuidadosa, permitindo que a criança exponha a sua realidade psíquica. O seu papel é fundamental na escolha do material e ambientação do espaço no processo ludodiagnóstico. Pois, esta escolha, feita adequadamente, estimula a criatividade da criança, a expressão de seus conteúdos internos de forma livre e a exposição de conflitos e fantasias. O que viabiliza um espaço facilitador para a ressignificação de conteúdos durante o processo.

\section{REFERÊNCIAS}

Affonso, L. R. (2012). Ludodiagnóstico: Investigação clínica através do brinquedo. São Paulo: Artmed.

Ferro, A. (1995). A técnica da psicanálise infantil: A criança e o analista da relação emocional (Justum, M., trad). Rio de Janeiro: Imago.

Lebovici, S. \& Diatkline, R. (1998). O significado e função do brinquedo na criança. Porto Alegre: Artes Médicas Sul Ltda.

Ocampo, M. L. S. (1999). O processo psicodiagnóstico e as técnicas projetivas. São Paulo: Martins Fontes.

Pickard, P.M. (1975). A criança aprende brincando (Gerte, N., trad.). São Paulo: IBRASA.

Severino, A. J. C. (2007). Metodologia do trabalho científico. 23a edição. São Paulo: Cortez. 
Trinca, W. et al. (1984). Diagnóstico psicológico: A prática clínica. 3a edição. São Paulo: EPU.

Winnicott, D. W. (1975). O brincar e a realidade. Rio de Janeiro: Imago.

Zimerman, D. E. (2008). Manual de técnica psicanalítica, uma re-visão. São Paulo: Artmed.

Contato: adrianatrapia@hotmail.com

Recebido em: 27/11/2012

Revisado em: 23/12/2012

Aceito em: 27/12/2012 